Medical Scope Journal (MSJ). 2019;1(1):31-35

Available from: https://ejournal.unsrat.ac.id/index.php/msj

\title{
Hubungan antara Posisi Kerja dan Usia dengan Keluhan Muskuloskeletal pada Pekerja Penyapu Jalan di Kecamatan Wenang Kota Manado
}

\author{
Brigita G. Imbar, Lery F. Suoth, Afnal Asrifuddin
}

Fakultas Kesehatan Masyarakat Universitas Sam Ratulangi Manado

Email: brigitaimbar27@gmail.com

\begin{abstract}
Musculoskeletal complaints could occur in parts of skeletal muscle ranging from very mild to very severe. If skeletal muscles receive static loads for a long time, muscle pain can occur. Street sweeper is a person whose job is to clean the road by using a broom. This study was aimed to determine whether there were relationships between work position and age and musculoskeletal complaints among street sweepers at Kecamaatan Wenang, Manado. This was a descriptive study. We used REBA for measuring work position; interview for age; and Nordic body map for musculoskeletal complaints. The Spearman test of the correlation between work position and musculoskeletal complaints obtained a p-value of 0.003 and an r-value of 0.381 with sufficiently weak correlation. Moreover, the Spearman test of the correlation between age and musculoskeletal complaints showed a p-value of 0.000 and an r-value of 0.529 with a moderate correlation. In conclusion, there was a relationship between work position and musculoskeletal complaints as well as between age and musculoskeletal complaints among street sweeper at Kecamatan Wenang, Manado.
\end{abstract}

Keywords: work position, age, musculoskeletal complaints

\begin{abstract}
Abstrak: Keluhan muskuloskeletal dirasakan oleh seseorang atau pekerja mulai dari keluhan sangat ringan sampai sangat hebat. Jika otot menerima beban statis untuk waktu yang cukup lama, maka dapat terjadi nyeri otot. Penyapu jalan bertugas untuk membersihkan jalanan dengan menggunakan sapu. Penelitian ini bertujuan untuk mengetahui adanya hubungan antara posisi kerja dan usia dengan keluhan muskuloskeletal pada pekerja penyapu jalan di Kecamatan Wenang Kota Manado. Jenis penelitian ialah deskriptif. Instrumen yang digunakan untuk pengukuran posisi kerja ialah REBA, sedangkan untuk pengukuran usia ialah wawancara dan untuk pengukuran keluhan muskuloskeletal menggunakan nordic body map. Hasil uji korelasi Spearman antara posisi kerja dan keluhan muskuloskeletal mendapatkan nilai $\mathrm{p}=0,003$ dan nilai $\mathrm{r}=0,381$ dengan kolerasi cukup lemah. Selain itu hasil uji korelasi antara usia dengan keluhan muskuloskeletal mendapatkan nilai $\mathrm{p}=0,000$ dan nilai $\mathrm{r}=0,529$ dengan korelasi sedang. Simpulan penelitian ini yaitu terdapat hubungan bermakna antara posisi kerja dan usia dengan keluhan muskuloskeletal pada pekerja penyapu jalan di Kecamatan Wenang.
\end{abstract}

Kata kunci: posisi kerja, usia, keluhan musculoskeletal

\section{PENDAHULUAN}

Terdapat hampir dua juta pekerja mengalami gangguan muskuloskeletal yang berhubungan dengan pekerjaan setiap tahun dan sekitar 600.000 kehilangan waktu bekerja. Keluhan muskuloskeletal merupakan masalah kesehatan yang tidak bisa disepelekan. Hasil Riskesdas tahun 2013 melaporkan bahwa gangguan muskuloskeletal berdasarkan diagnosis dan gejala yaitu sebesar 19,1\%. ${ }^{1}$ Gangguan muskuloskeletal bukan hanya menyebabkan masalah kesehatan tetapi juga memboroskan biaya pengobatan yang mahal sehingga mengakibatkan kerugian bagi perusahaan maupun keluarga dari pekerja tersebut. ${ }^{2}$ 
Prevalensi gangguan muskuloskeletal di Indonesia berdasarkan diagnosis oleh tenaga kesehatan yaitu $11,9 \%$ dan berdasarkan diagnosis atau gejala yaitu $24,7 \%$ di Provinsi Sulawesi Utara. International Labour Organization ${ }^{3}$ melaporkan bahwa gangguan muskuloskeletal saat ini mengalami peningkatan sekitar 4.000 kasus dalam kurun waktu 9 tahun dan di Inggris, 40\% kasus penyakit akibat kerja merupakan gangguan muskuloskeletal.

Faktor yang dapat menyebabkan terjadinya keluhan muskuloskeletal terdiri dari faktor pekerjaan, faktor individu, faktor lingkungan dan faktor psikososial, yang diantaranya meliputi sikap tubuh dalam bekerja. Terjadinya keluhan muskuloskeletal dapat juga dapat disebabkan karena pekerja bekerja dengan melakukan peregangan otot yang berlebihan, aktivitas yang berulang, dan sikap kerja yang tidak alamiah. $^{4}$

Pekerja penyapu jalan bekerja setiap hari untuk membersihkan jalan, termasuk trotoar dengan menggunakan sapu. Dari pengamatan sehari-hari sebagian penyapu jalan berjenis kelamin perempuan dan telah berusia pertengahan. Berdasarkan uraian di atas maka peneliti tertarik untuk mengetahui adanya hubungan antara posisi kerja dan usia dengan keluhan muskuloskeletal pada pekerja penyapu jalan di Kecamatan Wenang Kota Manado

\section{METODE PENELITIAN}

Penelitian ini dilakukan pada bulan Agustus- Oktober 2019 di wilayah Wenang Kota Manado. Jenis penelitian ini ialah survei analitik dengan desain potong lintang. Penelitian dilakukan dengan cara mengumpulkan data variabel bebas dan variabel terikat pada waktu yang bersamaan. ${ }^{5}$ Populasi penelitian ini sebanyak 58 pekerja penyapu jalan yang terdiri dari 10 laki-laki dan 48 perempuan. Data penelitian dianalisis menggunakan uji Spearman rank.

\section{HASIL PENELITIAN}

Tabel 1 memperihatkan karakteristik responden penelitian ini. Masa kerja tertinggi yaitu 1-4 tahun sebanyak 21 responden (36\%) sedangkan untuk masa kerja paling rendah yaitu 13-16 tahun dan 21-24 tahun, masing-masing sebanyak 1 responden $(2 \%)$.

Tabel 1. Karakteristik responden penelitian

\begin{tabular}{ccc}
\hline $\begin{array}{c}\text { Masa kerja } \\
\text { (tahun) }\end{array}$ & $\mathbf{n}$ & $\mathbf{\%}$ \\
\hline $1-4$ & 21 & 36 \\
$5-8$ & 18 & 31 \\
$9-12$ & 8 & 14 \\
$13-16$ & 1 & 2 \\
$17-20$ & 5 & 8 \\
$21-24$ & 1 & 2 \\
$24-28$ & 4 & 7 \\
Total & 58 & 100 \\
\hline
\end{tabular}

Tabel 2 menampilkan posisi kerja dengan tingkat risiko, yang tertinggi yaitu risiko tinggi sebanyak 46 responden (79,3\%) dan posisi yang paling rendah yaitu posisi kerja dengan tingkat risiko sedang sebanyak 2 responden (3,4\%).

Tabel 2. Tingkat risiko posisi kerja responden

\begin{tabular}{ccc}
\hline Posisi Kerja & n & \% \\
\hline Risiko sedang & 2 & 3,4 \\
Risiko tinggi & 46 & 79,3 \\
Risiko sangat & 10 & 17,2 \\
tinggi & 58 & 100 \\
Total &
\end{tabular}

Tabel 3 memperlihatkan pengelompokan usia yang dibagi menjadi 7 kelompok dengan menggunakan rumus Struges. Hasil pengukuran memperlihatkan bahwa yang terbanyak yaitu kelompok 46-51 tahun sebanyak 16 orang $(27,6 \%)$ dan yang paling sedikit ialah kelompok usia $>64$ tahun sebanyak 2 orang (3,4\%).

Tabel 3. Hasil pengukuran usia responden

\begin{tabular}{ccc}
\hline Usia (tahun) & $\mathbf{N}$ & $\mathbf{\%}$ \\
\hline 28-33 tahun & 5 & 8,6 \\
34-39 tahun & 7 & 12,1 \\
40-45 tahun & 10 & 17,2 \\
46-51 tahun & 16 & 27,6 \\
52-57 tahun & 14 & 24,1 \\
58-63 tahun & 4 & 6,9 \\
>64 tahun & 2 & 3,4 \\
Total & 58 & 100 \\
\hline
\end{tabular}


Tabel 4 menampilkan hasil pengukuran keluhan muskuloskeletal, yang tersering yaitu keluhan muskuloskeletal tinggi sebanyak 36 responden $(63,1 \%)$ dan yang paling sedikit yaitu keluhan muskuloskeletal sangat tinggi sebanyak 1 responden $(1,7 \%)$.

Tabel 4. Hasil pengukuran keluhan muskuloskeletal responden

\begin{tabular}{ccc}
\hline $\begin{array}{c}\text { Keluhan } \\
\text { muskuloskeletal }\end{array}$ & $\mathbf{n}$ & $\mathbf{\%}$ \\
\hline Sedang & 21 & 36,2 \\
Tinggi & 36 & 63,1 \\
Sangat tinggi & 1 & 1,7 \\
Total & 58 & 100 \\
\hline
\end{tabular}

Tabel 5 menunjukkan hasil uji Spearman rank yang memperoleh nilai $\mathrm{p}=0,003$, yang menyatakan terdapat hu- bungan antara posisi kerja dengan keluhan muskuloskeletal pada pekerja penyapu jalan di Kecamatan Wenang Kota Manado dengan korelasi cukup lemah $(r=0,381)$. Hal ini berarti semakin tinggi risiko posisi kerja penyapu jalan, maka keluhan muskuloskeletal semakin tinggi juga dirasakan.

Tabel 6 mamaparkan hasil uji Spearman rank yang memperoleh nilai $\mathrm{p}=0,000$. Hal ini menunjukkan bahwa terdapat hubungan bermakna antara usia dengan keluhan muskuloskeletal pada pekerja penyapu jalan di Kecamatan Wenang Kota Manado dengan korelasi sedang $(r=0,529)$. Dapat disimpulkan bahwa usia responden terbanyak yaitu usia 40-45 tahun dengan jumlah 7 orang $(12,1 \%)$ yang mengalami keluhan muskuloskeletal sedang.

Tabel 5. Hubungan posisi kerja dengan keluhan muskuloskeletal pada responden

\begin{tabular}{ccccccccccc}
\hline & \multicolumn{3}{c}{ Keluhan muskuloskeletal } & \multicolumn{5}{c}{ Total } & Nilai p & r \\
$\begin{array}{c}\text { Posisi } \\
\text { kerja }\end{array}$ & Sedang & $\%$ & Tinggi & $\%$ & $\begin{array}{c}\text { Sangat } \\
\text { tinggi }\end{array}$ & $\%$ & $\mathrm{n}$ & $\%$ & & \\
\hline $\begin{array}{c}\text { Risiko } \\
\text { sedang }\end{array}$ & 2 & 3,44 & 0 & 0 & 0 & 2 & 2 & 3,44 & & \\
$\begin{array}{c}\text { Risiko } \\
\text { tinggi }\end{array}$ & 19 & 32,7 & 26 & 44,8 & 1 & 1,7 & 46 & 79,31 & 0,003 & 0,381 \\
$\begin{array}{c}\text { Risiko } \\
\text { sangat }\end{array}$ & 0 & 0 & 10 & 17,2 & 0 & 0 & 10 & 17,24 & & \\
tinggi & & & & & & & & & & \\
Total & 21 & 36,1 & 36 & 62 & 1 & 3,7 & 58 & 100 & & \\
\hline
\end{tabular}

Tabel 6. Hubungan antara usia dengan keluhan muskuloskeletal

\begin{tabular}{ccccccccccc}
\hline & \multicolumn{3}{c}{ Keluhan muskuloskeletal } & & & Total & & $\begin{array}{c}\text { Nilai } \\
\mathbf{p}\end{array}$ & $\begin{array}{c}\text { Nilai } \\
\mathbf{r}\end{array}$ \\
$\begin{array}{c}\text { Usia } \\
\text { (tahun) }\end{array}$ & Sedang & $\%$ & Tinggi & $\%$ & $\begin{array}{c}\text { Sangat } \\
\text { tinggi }\end{array}$ & $\%$ & $\mathrm{~N}$ & $\%$ & & \\
\hline $28-33$ & 5 & 8,6 & 0 & 0 & 0 & 0 & 5 & 8,6 & & \\
$34-39$ & 4 & 6,9 & 3 & 5,2 & 0 & 0 & 7 & 12,1 & & \\
$40-45$ & 7 & 12,1 & 3 & 5,2 & 0 & 0 & 10 & 17,2 & & \\
$46-51$ & 2 & 5,9 & 13 & 9,9 & 1 & 2 & 16 & 16 & 0,000 & 0,529 \\
$52-57$ & 3 & 5,1 & 11 & 8,7 & 0 & 0 & 14 & 14 & & \\
$58-63$ & 0 & 0 & 4 & 6,9 & 0 & 0 & 4 & 6,9 & & \\
$>64$ & 0 & 0 & 2 & 1,2 & 0 & 0 & 2 & 1,2 & & \\
Total & 21 & 36,2 & 36 & 62,1 & 1 & 1,7 & 58 & 100 & & \\
\hline
\end{tabular}




\section{BAHASAN}

Pada penelitian ini didapatkan bahwa masa kerja tertinggi dari responden ialah 14 tahun (36\%) sedangkan untuk masa kerja yang paling rendah ialah 13-16 tahun dan 21-24 tahun (masing-masing 2\%) (Tabel 1). Posisi kerja dengan tingkat risiko yang tertinggi ialah risiko tinggi $(79,3 \%)$ dan posisi yang paling rendah yaitu posisi kerja dengan tingkat risiko sedang (3,4\%) (Tabel 2). Pengelompokan usia dibagi menjadi 7 kelompok dengan menggunakan rumus Struges dan yang terbanyak yaitu 46-51 tahun $(27,6 \%)$ dan usia paling rendah yaitu $>64$ tahun (3,4\%) (Tabel 3). Hasil pengukuran keluhan muskuloskeletal yang terbanyak yaitu keluhan muskuloskeletal tinggi $(63,1 \%)$ dan yang paling sedikit yaitu keluhan muskuloskeletal sangat tinggi (1,7\%) (Tabel 4).

Hasil uji Spearman rank mendapatkan nilai $\mathrm{p}=0,003$ yang menunjukkan adanya hubungan antara posisi kerja dengan keluhan muskuloskeletal pada pekerja penyapu jalan di Kecamatan Wenang Kota Manado (Tabel 5). Korelasi tersebut tergolong cukup lemah $(r=0,381)$ yang berarti semakin tinggi risiko posisi kerja penyapu jalan, maka keluhan muskuloskeletal semakin tinggi dirasakan. Hasil ini sejalan dengan penelitian yang dilakukan oleh Semau et $\mathrm{al}^{6}$ terhadap nelayan di Kelurahan Malalayang 1 Timur Kecamatan Kota Manado yang mendapatkan nilai $\mathrm{p}=0,001$ untuk hubungan antara posisi kerja dengan keluhan muskuloskeletal. Hasil penelitian tersebut juga menunjukkan bahwa semakin tinggi risiko posisi kerja pada nelayan maka para pekerja mengalami keluhan muskuloskeletal yang semakin tinggi juga.

Hasil uji Spearman rank terhadap hubungan antara usia dengan keluhan muskuloskeletal pada pekerja penyapu jalan di Kecamatan Wenang Kota Manado memperoleh nilai $\mathrm{p}=0,000$ yang menunjukkan adanya hubungan antara usia dengan keluhan muskuloskeletal dengan korelasi sedang $(\mathrm{r}=0,529)$ (Tabel 6) sehingga dapat disimpulkan bahwa usia terbanyak dari penyapu jalan yaitu usia 40-45 tahun $(12,1 \%)$ yang mengalami keluhan muskulo- skeletal sedang. Hasil penelitian ini selaras dengan penelitian yang dilakukan oleh Taroreh $^{7}$ yang melaporkan terdapatnya hubungan antara usia dengan keluhan muskuloskeletal pada kusir bendi di Tomohon $(p=0,004 ; r=0,327)$. Semakin tinggi usia, maka semakin besar keluhan muskuloskeletal. Hasil penelitian ini juga sejalan dengan penelitian oleh Krisdianto et $\mathrm{al}^{8}$ yang menyatakan terdapat hubungan antara usia dengan keluhan muskuloskeletal pada nelayan di Desa Puger Wetan Kecamatan Puger Kabupaten Jember $(\mathrm{p}=0,000)$.

\section{SIMPULAN}

Berdasarkan hasil penelitian ini dapat disimpulkan bahwa terdapat hubungan antara posisi kerja dengan keluhan muskuloskeletal pada pekerja penyapu jalan di Kecamatan Wenang Kota Manado dengan kolerasi cukup lemah, artinya semakin tingkat posisi kerja maka semakin tinggi keluhan muskuloskeletal yang dirasakan. Juga terdapat hubungan antara usia dengan keluhan muskuloskeletal pada pekerja penyapu jalan di Kecamatan Wenang Kota Manado dengan korelasi sedang, artinya semakin tua usia pekerja penyapu jalan maka semakin bertambah keluhan muskuloskeletal yang dirasakan.

Bagi para penyapu jalan disarankan agar memperhatikan posisi saat bekerja menyapu jalan agar tidak mengakibatkan keluhan muskuloskeletal. Sebaiknya sebelum menyapu jalan, pekerja disarankan melakukan relaksasi seperti olahraga dengan peregangan otot jika merasakan keluhan-keluhan muskuloskeletal.

\section{DAFTAR PUSTAKA}

1. Laporan Hasil Riset Kesehatan Dasar 2013. Jakarta: Badan Penelitian dan Pengembangan Kesehatan Kementerian Kesehatan RI. Available from: https://depkes.go.id/resources/downloa d/general/Hasil\%20Riskesdas\%202013 .pdf

2. Sekaaram A. 2017. Prevalensi muskuloskeletal disorders (MSDs) pada pengemudi angkutan umum di terminal Mengwi, Kabupaten Bandung-Bali. Available 
from: https://isainsmedis.id/index.php/ ism/article/viewFile/125/140

3. International Labur Organization. Safety and health at work: a vision for sustainable prevention. ILO, 2014. Available from: https://www.ilo.org/wcmsp5/groups/pu blic/---ed_protect/---protrav/--safework/documents/publication/wcms _301214.pdf

4. Russeng S, Rafael D, Asni S. Hubungan postur kerja dengan keluhan muskuloskeletal disorders (MSDs) pada pemanen kelapa sawit di PT Sinergi Perkebunan Nusantara. Jurnal Fakultas Kesehatan Masyarakat Universitas Hasanuddin Makassar. 2013. Available from: http://repository.unhas.ac.id/bitstream/h andle/123456789/8615/ASNI\%20SAN G\%20(K11109291).pdf?sequence=1

5. Notoatmodjo S. Metode Penelitian Kesehatan. Jakarta: Rineka Cipta, 2012.

6. Semau J. Ratag BT, Josephus J. 2013. Hubungan posisi kerja dengan keluhan musculoskeletal pada nelayan di Kelurahan Malalayang 1 Timur Kecamatan Malalayang Kota Manado. Available from: http://medkesfkm. unsrat.ac.id/wp-content/uploads/ 2016/05/Joscelin-Samau.pdf

7. Taroreh FF. Hubungan antara umur dan masa kerja dengan keluhan musculoskeletal pada kursi bendi [Skripsi]. Manado: Fakultas Kesehatan Masyarakat, Universitas Sam Ratulangi Manado; 2017.

8. Krisdianto A, Dewi PS, Ismi H. 2015. Hubungan faktor individu dan faktor pekerjaan dengan keluhan musculoskeletal akibat kerja (Studi pada nelayan di Desa Puger Wetan Kecamatan Puger Kabupaten Jember) [Artikel ilmiah hasil penelitian mahasiswa]. Available from: http: //repository.unej.ac.id/bitstream/handle/ 123456789/74523/Krisdianto.pdf?sequ ence $=1$ 